\title{
Triplet luminescent dinuclear-gold $(I)$ complex-based light-emitting diodes with low turn-on voltage
}

\author{
Yuguang $\mathrm{Ma}^{\mathrm{a}}{ }^{\mathrm{a}}$ Xuemei Zhou, and Jiacong Shen \\ Key Lab for Supramolecular Structure and Spectra, Jilin University, Changchun 130023, \\ People's Republic of China \\ Hsiu-Yi Chao and Chi-Ming Che ${ }^{\text {b) }}$ \\ Department of Chemistry, The University of Hong Kong, Pokfulam Road, Hong Kong
}

(Received 14 September 1998; accepted for publication 12 January 1999)

\begin{abstract}
The electroluminescence (EL) from a dinuclear-gold(I)-chlorate compound containing bridging phosphine ligands $\left[\mathrm{Au}_{2}(\mathrm{dppm}) \mathrm{Cl}_{2}\right]$ as emitting layer is reported. Devices with a structure $\mathrm{Al} / \mathrm{Au}_{2}(\mathrm{dppm}) \mathrm{Cl}_{2}$ /indium-tin-oxide demonstrated a uniform emission under the driving voltage below $1 \mathrm{~V}$. The EL emission was from triplet excited state and the emission color of the device was found to depend on the deposition rate of $\mathrm{Au}_{2}(\mathrm{dppm}) \mathrm{Cl}_{2}$, which can be explained as the different aggregation forms of the stacking compound in the deposition process. (C) 1999 American Institute of Physics. [S0003-6951(99)03710-9]
\end{abstract}

In the development of new and high-performance electroluminescent materials, considerable attention has been directed mainly to the construction of $\pi$-conjugated polymeric systems $^{1,2}$ and main group metal-ligand complexes, ${ }^{3,4}$ and yet the analogous studies on transition metal-ligand compounds are sparse. In this context, luminescent gold $(I)$ compounds are of considerable interest. This class of compounds are readily prepared, stable to air and moisture, and display long-live intense photoluminescence at room temperature. ${ }^{5-13}$ Furthermore, their emission energies can span over a broad spectral range by changing the auxiliary ligands, the coordination geometry, and the extent of the $\operatorname{gold}(I)-\operatorname{gold}(I)$ interaction (aurophilicity) in the molecule. 5,6,13 Although some interesting applications of luminescent gold $(I)$ complexes as chemical sensors have recently emerged, ${ }^{14}$ to our knowledge, molecular light-emitting diode (LED) devices based on luminescent gold $(I)$ compounds have few precedents in literature. Herein is described the applications of luminescent gold $(I)$ complex in the fabrication of LED devices.

As representative example, the $\operatorname{gold}(I)$ complex $\mathrm{Au}_{2}(\mathrm{dppm}) \mathrm{Cl}_{2}$ was chosen in this work. The $\mathrm{Au}_{2}(\mathrm{dppm}) \mathrm{Cl}_{2}$ used here was synthesized according to a previously method $^{10,15,16}$ and its structure was characterized by x-ray crystal analysis and is depicted in Fig. 1. The basic photophysical data of $\mathrm{Au}_{2}(\mathrm{dppm}) \mathrm{Cl}_{2}$ in solution, solid state, and in poly(methyl methacrylate) (PMMA) matrix are summarized in Table I. The long lifetimes of excited state $(0.3 \mu \mathrm{s})$ and large Stokes shift $(317 \mathrm{~nm})$ of absorption and emission indicated the emission was from the triplet excited. On the basis of the emission spectra and emission lifetimes and theoretical chemistry calculation, ${ }^{17,18}$ the emission state of dinuclear gold $(I)$ complexes has been assigned as the triplet metal center ${ }^{3} \mathrm{MC}$ state, which means that the highest occupied mo-

\footnotetext{
${ }^{a)}$ Electronic mail: ygma@mail.jlu.edu.cn
}

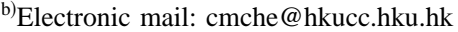

lecular orbital (HOMO) and lowest occupied molecular orbital (LUMO) mainly consist from the orbital of gold $(I)$ ion.

A single-layer LED was prepared using $\mathrm{Au}$ complexes as the emitting layer, and the cell structure $\left[\mathrm{Al} / \mathrm{Au}_{2}(\mathrm{dppm}) \mathrm{Cl}_{2}\right.$ /indium-tin-oxide (ITO) $]$ is schematically shown in Fig. 1 . The $\mathrm{Au}_{2}(\mathrm{dppm}) \mathrm{Cl}_{2}$ was electrical neutrality and volatility and is suitable for vacuum deposition method. The $\mathrm{Au}_{2}(\mathrm{dppm}) \mathrm{Cl}_{2}$ was subjected to vacuum of $\sim 6.67 \times 10^{-4} \mathrm{~Pa}$ and deposited onto a glass substrate precoated with an ITO (sheet resistance 30-50 $\Omega / \square$ ) at a rate of 0.05 and $0.1 \mathrm{~nm} \mathrm{~s}^{-1}$ to form a thin film of thickness $\sim 70 \mathrm{~nm}$. The thickness and the deposition rate were monitored with a quartz oscillator. The error of the thickness was about $\pm 10 \%$ which was mainly due to the error of the density of $\mathrm{Au}(I)$ compound. An aluminum cathode was then deposited on the $\mathrm{Au}(I)$ film at vacuum. The electrode area of the EL device was $2 \times 5 \mathrm{~mm}^{2}$.

The absorption and photoluminescence spectra (Fig. 2) of the thin film devices reveal signification difference for the devices furnished at deposition rate of 0.05 (I) and $0.1 \mathrm{~nm} / \mathrm{s}$ (II). For instance, the absorption maxim at 268 and $276 \mathrm{~nm}$ could be indicative of different extent of $\mathrm{Au}-\mathrm{Au}$ interactions
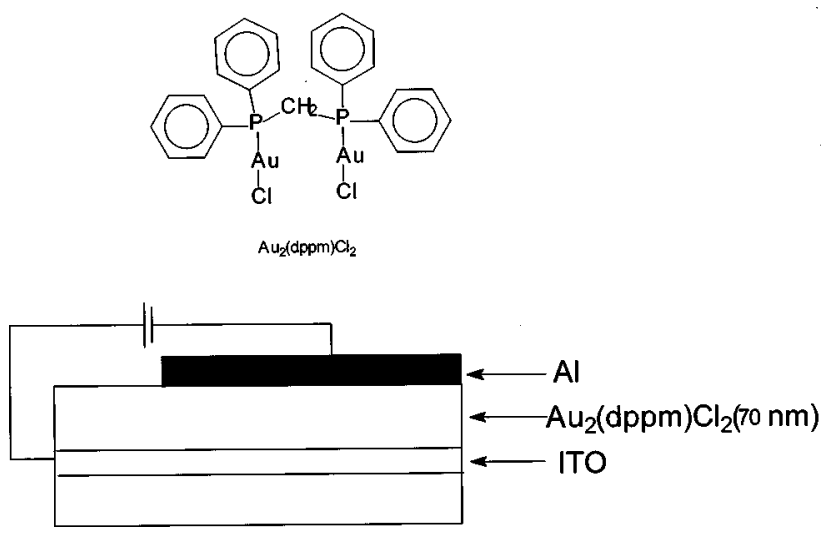

FIG. 1. The device and molecular structure of $\mathrm{Au}_{2}(\mathrm{dppm}) \mathrm{Cl}_{2}$. 
TABLE I. Summary of the spectroscopy properties of $\mathrm{Au}_{2}(\mathrm{dppm}) \mathrm{Cl}_{2}$ in acetonitrile solution, in solid state, and in PMMA matrix. The $\lambda_{\text {abs }}$ and $\lambda_{\text {em }}$ represent the absorption and emission wavelength. The $\epsilon_{\max }$ is absorption coefficient. The $\tau$ and $\phi$ are the lifetime of excited state and quantum yield of emission, respectively.

\begin{tabular}{ccccc}
\hline \hline Complexes & $\begin{array}{c}\lambda_{\text {abs }}(\mathrm{nm}) / \epsilon_{\max } \\
\left(\mathrm{M}^{-1} \mathrm{~cm}^{-1}\right)\end{array}$ & $\begin{array}{c}\lambda_{\text {em }}(\mathrm{nm}) / \tau(\mu \mathrm{s}), \phi \\
\text { in solution }\end{array}$ & $\begin{array}{c}\lambda_{\text {em }}(\mathrm{nm}) / \tau(\mu \mathrm{s}) \\
\text { in solid state }\end{array}$ & $\begin{array}{c}\lambda_{\text {em }}(\mathrm{nm}) / \tau(\mu \mathrm{s}) \\
\text { in PMMA }\end{array}$ \\
\hline $\mathrm{Au}_{2}(\mathrm{dppm}) \mathrm{Cl}_{2}$ & $268 / 28100$ & $585 / 0.3,0.15$ & $580 / 0.3$ & $520 / 0.45$ \\
\hline \hline
\end{tabular}

in the two films. In accordance with this, the photoluminescence of the film samples are also different; II shows a yellow-green color $\left(\lambda_{\mathrm{em}}=517 \mathrm{~nm}\right)$, and yet magenta color $\left(\lambda_{\mathrm{em}}=575 \mathrm{~nm}\right)$ is observed for I. The significant difference in emission color may be related to supramolecular structure (stacking structure) of the deposition films. However, the exact reason for this is not clear. We postulate that conversion from syn-syn to syn-anti orientation and/or the extent of $\operatorname{gold}(I)-\operatorname{gold}(I)$ interaction in the deposition films may act for the electronic structure. It is well known that $\mathrm{Au}(I)$ dimmers containing $\mathrm{P}$ and $\mathrm{C}$ donor bridging ligands, possess a strong propensity to aggregate and form chains with short intermolecular $\operatorname{gold}(I)-\operatorname{gold}(I)$ contacts, and the samples with the same intramolecular $\operatorname{gold}(I)-\operatorname{gold}(I)$ distance but different intermolecular gold $(I)-\operatorname{gold}(I)$ distance show a very large spectra difference. ${ }^{5,11}$ For example, the crystal sample of $\mathrm{Au}_{2}(\mathrm{dppm}) \mathrm{Cl}_{2}$ shows the emission at $575 \mathrm{~nm}$, while the sample of $\mathrm{Au}_{2}(\mathrm{dppm}) \mathrm{Cl}_{2}$ doped PMMA which can be considered as a matrix where intermolecular interaction and complexes/solvent interaction are diminished, shows a yellow green emission with emission peak at $520 \mathrm{~nm}$.

When the single-layer devices I and II are forward biased with the ITO electrode at positive polarity; electroluminescence was observed, and the EL spectra at various applying voltages are shown in Fig. 3. As for typical molecule LEDs, the emission intensity increases linearly with the injection current for both devices. Device I shows magenta emission $\left(\lambda_{\mathrm{em}}=580 \mathrm{~nm}\right)$ upon application of an external voltage, and II exhibits a yellow-green emission $\left(\lambda_{\mathrm{em}}\right.$ $=520 \mathrm{~nm}$ ). The resemblance of the EL and PL spectra suggests a common excited state. The brightness at a current density $100 \mathrm{~mA} / \mathrm{cm}^{2}$ is $25 \mathrm{~cd} / \mathrm{m}^{2}$ and estimated EL yield is
$<0.1 \%$. We envisage that the optimization of the cell structure should bring about higher brightness. The HOMO and LUMO of gold $(I)$ complexes are contributed mainly from the orbital of $\operatorname{gold}(I)$ ion, and the gold $(I)$ ion should be the sites trapped electrons and holes. The recombination of trapped electrons and holes in complexes result in the formation of excited state, which should be a triplet in nature. In our recent reports, ${ }^{19}$ we have emphasized that because the formation efficiency of triplet state will be tripled of singlet state in the nongeminate pair electron combination (as in EL), the improving EL yield should be predicted by using triplet state materials as the emitting layer. According to this, we can predict $\operatorname{gold}(I)$ complex can be advance materials to improve the EL efficiency.

The current-voltage $(I-V)$ characteristics of I and II are depicted in Fig. 4; we are gratified that both devices show very low turn-on voltage (below $1 \mathrm{~V}$ for $70 \mathrm{~nm}$ thickness device and threshold field $\left.1.4 \times 10^{5} \mathrm{~V} / \mathrm{cm}\right)$. Compared with other related examples such as tris(8-hydroxyquinolinato) aluminum $^{3}$ and poly $(p \text {-phenylene vinylene })^{1,20}$ which require far higher turn-on voltages $(>5 \mathrm{~V})$ to effect electroluminescence. The results indicated that a low carrier injection barrier and large carriers mobility are in Au complexes devices. Observed $I-V$ characteristics should be related the intra- and intermolecular gold $(I)-\operatorname{gold}(I)$ interaction, which possibly provide the new tunnels for the carriers transport, resulting in low resistant and large charge mobility.

In conclusion, we found that the $\operatorname{gold}(I)$ complex $\mathrm{Au}_{2}(\mathrm{dppm}) \mathrm{Cl}_{2}$ was an interesting materials for LEDs, which exhibit very low turn-on voltage and dependence of emission

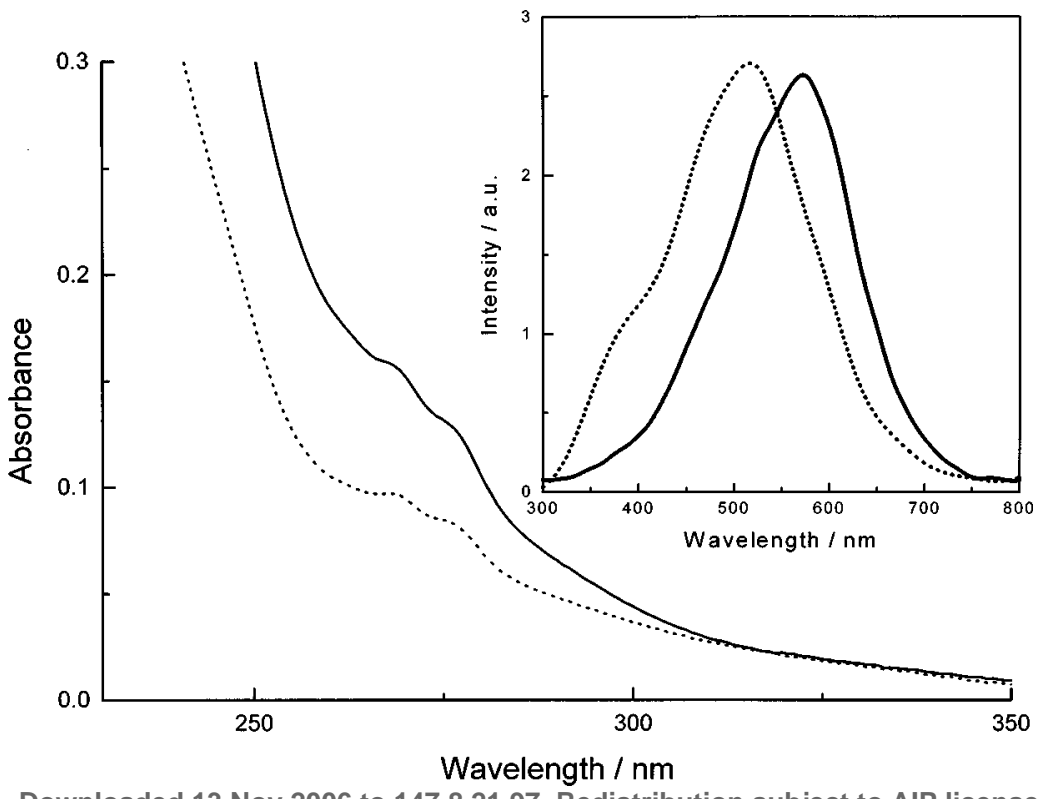

FIG. 2. The absorption spectra of $\mathrm{Au}_{2}(\mathrm{dppm}) \mathrm{Cl}_{2}$ deposition films prepared by different deposition rate 0.05 (solid line) and $0.1 \mathrm{~nm} / \mathrm{s}$ (dotted line). Insert was the PL spectra of the corresponding films, excitation at 290 nm. 


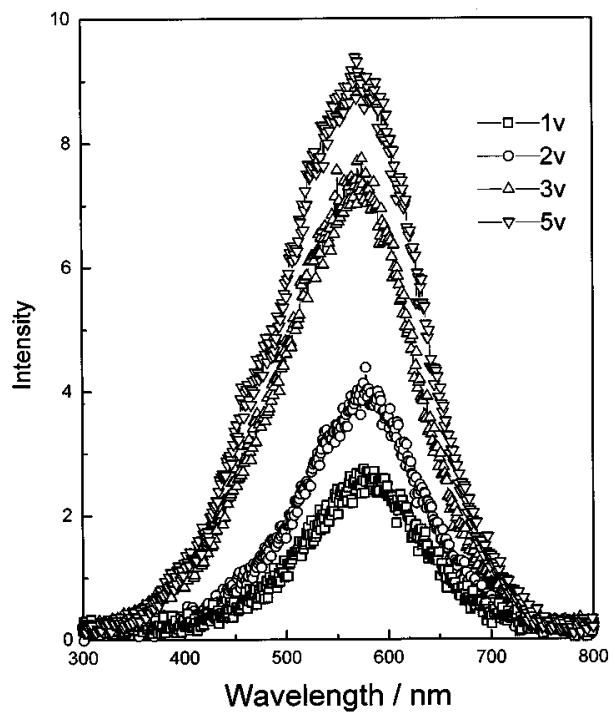

(a)

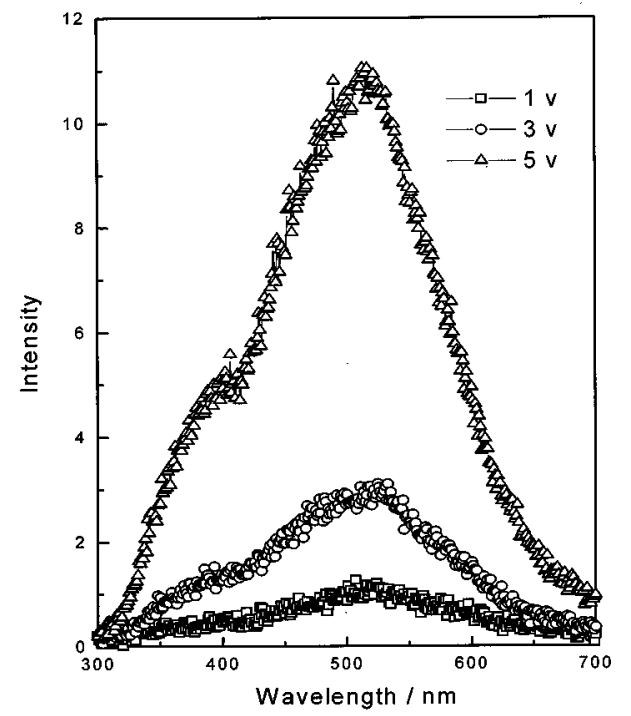

(b)
FIG. 3. EL spectra of cell $\mathrm{ITO} / \mathrm{Au}_{2}(\mathrm{dppm}) \mathrm{Cl}_{2} / \mathrm{Al}$ prepared by different $\mathrm{Au}_{2}(\mathrm{dppm}) \mathrm{Cl}_{2}$ deposition rate (a) 0.05 and (b) $0.1 \mathrm{~nm} / \mathrm{s}$. spectra on the molecular and/or supramolecular structure of gold $(I)$ complexes layer. The results suggest a possible application of this class of luminescent gold complex with triplet excited state for the electroluminescent devices.

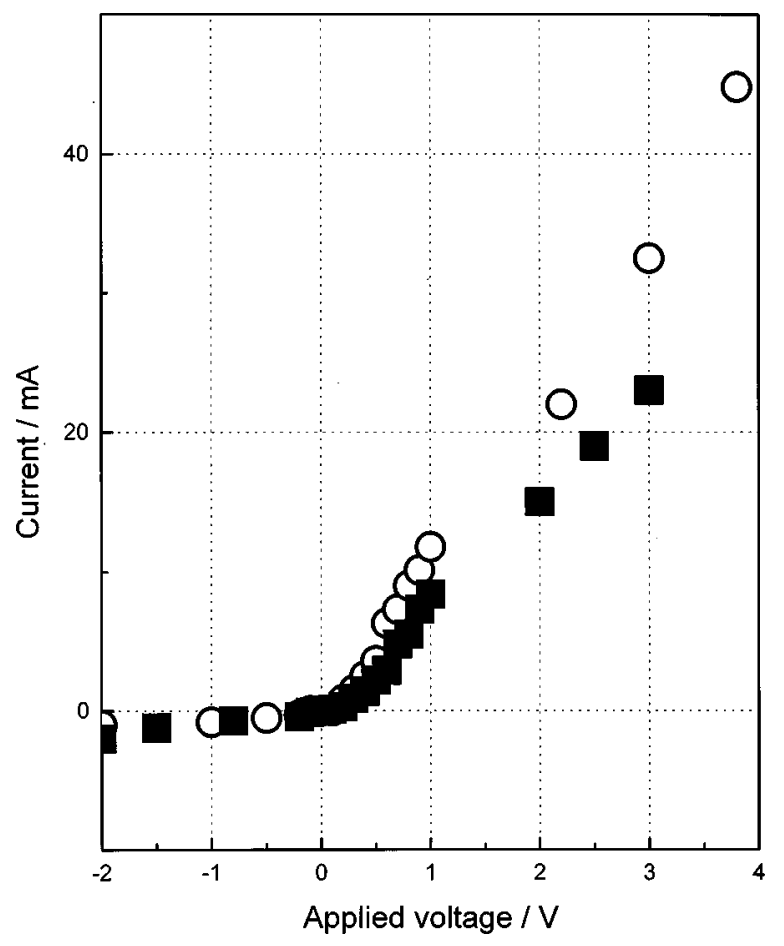

FIG. 4. The $I-V$ characteristics of $I T O / \mathrm{Au}_{2}(\mathrm{dppm}) \mathrm{Cl}_{2} / \mathrm{Al}$ device prepared by different $\mathrm{Au}_{2}(\mathrm{dppm}) \mathrm{Cl}_{2}$ deposition rate, 0.05 (cycle) and $0.1 \mathrm{~nm} / \mathrm{s}$ (square).
The authors would like to acknowledge the National Science Foundation of China, the University of Hong Kong, the Hong Kong Research Grants Council, and the Croucher Foundation for funding for this project.

${ }^{1}$ C. W. Tang and S. A. VanSlyke, Appl. Phys. Lett. 51, 913 (1987).

${ }^{2}$ J. H. Burroughes, D. D. C. Brandley, A. R. Brown, R. N. Marks, K. Mackay, R. H. Friend, P. L. Burn, and A. B. Holmes, Nature (London) 347, 539 (1990).

${ }^{3}$ D. Braun and A. J. Heeger, Appl. Phys. Lett. 58, 1982 (1991).

${ }^{4}$ Y. Hamada, H. Kanno, T. Sano, H. Fujii, Y. Nishio, H. Takahashi, T. Usuki, and K. Shibata, Appl. Phys. Lett. 72, 1939 (1998).

${ }^{5}$ C. M. Che, W. T. Wong, T. F. Lai, and H. L. Kwong, J. Chem. Soc. Chem. Commun., 243 (1989).

${ }^{6}$ C. M. Che, H. L. Kwong, V. W. W. Yam, and K. C. Cho, J. Chem. Soc. Chem. Commun., 885 (1989).

${ }^{7}$ C. M. Che, H. L. Kwong, C. K. Poon, and V. W. W. Yam, J. Chem. Soc. Dalton Trans., 3215 (1990).

${ }^{8}$ V. W. W. Yam and C. M. Che, J. Chem. Soc. Dalton Trans. , 3747 (1990).

${ }^{9}$ S. J. Shied, H. Xiao, S. M. Peng, and C. M. Che, J. Chem. Soc. Dalton Trans., 3067 (1994).

${ }^{10}$ Hong Xiao, Ph.D. thesis, University of Hong Kong, 1997.

${ }^{11}$ C. King, J. C. Wang, M. N. I. Khan, and J. P. Fackler, Jr., Inorg. Chem. 28, 2145 (1989).

${ }^{12}$ Z. Assefa, R. J. Staples, and J. P. Fackler, Jr., Inorg. Chem. 33, 2790 (1994).

${ }^{13}$ M. J. Irwin, J. J. Vittal, and R. J. Puddephatt, Organometallics 16, 3541 (1997).

${ }^{14}$ Y. Kunugi, K. R. Mann, L. L. Miller, and C. L. Exstrom, J. Am. Chem. Soc. 120, 589 (1998)

${ }^{15}$ H. Schmidbaur, W. Graf, and G. Muller, Angew. Chem. Int. Ed. Engl. 27, 417 (1988).

${ }^{16}$ H. Schmidbaur, A. Wohlleben, F. Wagner, O. Orama, and G. Huttner, Chem. Ber. 110, 1748 (1977).

${ }^{17}$ Y. Jiang, S. Alvarez, and R. Hoffmann, Inorg. Chem. 24, 749 (1995).

${ }^{18}$ T. Ziegler, J. G. Snijders, and E. J. Baerends, J. Chem. Phys. 74, 1271 (1981).

${ }^{19}$ Y. G. Ma, H. Y. Zhang, J. C. Shen, and C. M. Che, Synth. Met. 94, 245 (1998).

${ }^{20}$ K. M. Vaeth and K. F. Jensen, Appl. Phys. Lett. 71, 2091 (1997). 